\title{
It's input that matters most, not age
}

JAMES EMIL FLEGE

School of Health Professions, University of Alabama at Birmingham

(Received: December 20, 2017; final revision received: January 20, 2018; accepted: January 20, 2018; first published online 15 May 2018)

The splendid review provided by Mayberry and Kluender (2017) confirms Lenneberg's 1967 hypothesis that a Critical Period (CP) exists for the establishment of a native language. However, Lenneberg's extension of the $\mathrm{CP}$ hypothesis to the later learning of an $\mathrm{L} 2$, based on his observation that most individuals who learn an L2 after about the age of 13 speak it with a foreign accent (FA), is doubtful.

The now rich literature on FA in immigrants does not support predictions deriving from the $\mathrm{CP}$ hypothesis. There is no discontinuity at or near 13 years of age in the relation between age of arrival (AOA) in the host country and strength of FA, and strength of FA continues to increase after the age of 13. For example, Flege and MacKay (2011) found significant FA differences between Italians with AOAs of 10 vs. 18 years and 18 vs. 26 years. The CP hypothesis might account for the first but not the second difference. Nor does the CP hypothesis predict the presence of FA in individuals who learned the L2 as young children (Flege, Birdsong, Bialystok, Mack, Sung \& Tsukada, 2006), even after decades of L2 use (Flege, MacKay \& Munro, 1995; Flege, Yeni-Komshian, G., \& Liu, 1999). Flege, Frieda and Nozawa (1997) found that two groups of Italian adults having AOAs of 6 years were foreign-accented, and their strength of FA depended on frequency of Italian use.

Most importantly, the $\mathrm{CP}$ hypothesis fails to predict the L2-inspired FA found in native language (L1) production (Flege, 2007). Cross-language phonetic interference in bilinguals is necessarily bi-directional. The phonetic elements making up bilinguals' L1 and L2 phonetic subsystems interact because they co-exist in a finite phonological "space".

Lenneberg's (1967) was correct in saying that FAs are commonplace after age 13, but this may arise from changes in input rather than to a loss of capacity for speech learning, itself an unwanted consequence of normal neural maturation. Immigrants' AOA conditions their experience in the L2. For example, Flege et al. (1995) found that Italians who arrived in Canada up until the age of 14 years soon began attending school, where they learned English mostly from native English (NE) classmates and established a rich network of NE-speaking friends. Those

Address for correspondence:

School of Health Professions, University of Alabama at Birmingham jeflege@uab.edu arriving slightly later in life went to work, learning English mostly from other Italians. Among Early learners, women had milder FAs than did men. For Late learners, on the other hand, women had stronger FAs than men did because they worked at home and learned English mostly from male relatives who worked outside the home.

AOA also conditions the QUANTITY of input immigrants receive. Studies that examined 240 Italian and Korean immigrants each (Flege et al., 1995, 1999) showed large shifts in the relative frequency of L1 and L2 use at an AOA of about 13 years. Such shifts are due to social factors, not neural maturation.

Mayberry and Kluender (2017) note the difficulty of disentangling effects due to age and input. One solution is after-the-fact analysis. For example, Flege et al. (1999) replicated Johnson and Newport's (1989) AOA effect on Korean's knowledge of English morphosyntax using their stimuli and procedures. However, the AOA effect disappeared when factors confounded with AOA were controlled using a subgroup matching technique.

Flege and MacKay (2004) used a prospective design to examine the perception of English /i/ and / / / by Italians differing orthogonally in AOA (8 vs 20 years) and percent Italian use ( $8 \%$ vs $48 \%$ ). Italians having little experience in English tend to produce these two English vowels interchangeably because they hear both vowels as instances of their Italian /i/ category.

Figure 1(a) shows the mean discrimination of $/ \mathrm{i} / \mathrm{-}$ /I/. Just one Italian group, the Late learners who used Italian often (LH), differed significantly from the NE speakers. Importantly, however, members of this group discriminated the English vowels much better than young adults who had studied English for 9 years in Italy and 3 months in Canada.

The roles of age and input were evaluated in a stepwise regression analysis. AOA correlated significantly with years of residence and schooling in Canada $(r=-0.66$, $-0.86)$. Self-estimated overall percent use of Italian correlated with number of interlocutors in Italian $(r=$ $0.44)$ and the median of Italian use estimates in ten specific social contexts $(r=0.90)$. Just two of six variables predicted discrimination accuracy: median Italian use ( $19 \%$ of variance) followed by AOA (7\%).

Figure 1(b) shows the results of an error detection task. The stimuli consisted of spontaneous phrases produced by Italian immigrants. In one block the target vowel was /i/ (e.g., sp*k the), produced either correctly or as /I/. 


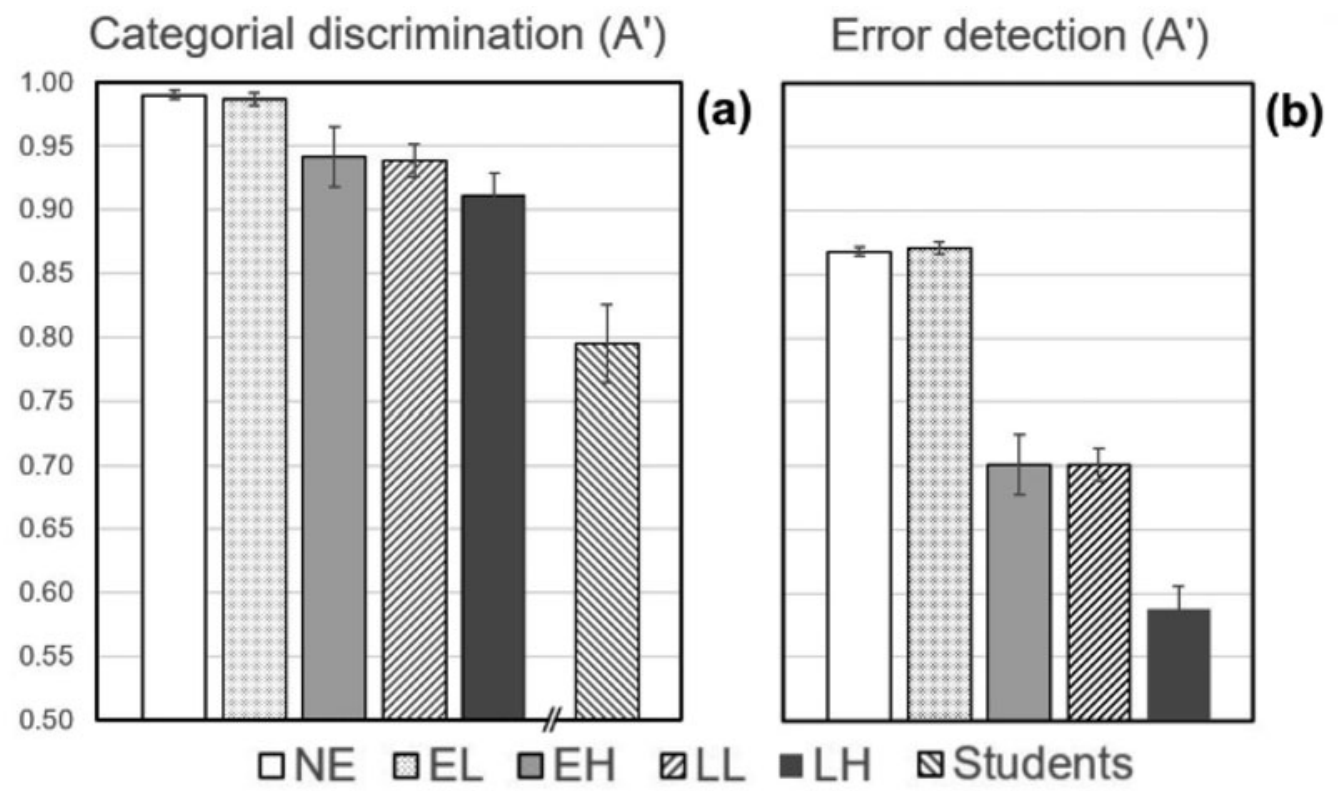

Figure 1. (a) Discrimination and (b) error detection of English /i/ and /I/ by groups of Italians differing orthogonally in age of arrival in Canada (Early vs. Late) and amount of Italian use (Low vs $\underline{\text { High }}$ ). The error bars bracket $+/-1$ SEM.

The target vowel in the other block was /I/ (e.g., a $c * t y)$ produced correctly or as /i/. Participants had to decide if the target vowel in each auditorily and visually presented phrase had been produced correctly or incorrectly. The difference between NE speakers and Early learners who used Italian often $(\mathrm{EH})$, and the LACK of a difference between the Early and Late learners in groups EH and LL, are incompatible with the CP hypothesis.

Some effects attributed to age of L2 exposure may be due to uncontrolled variation in the quantity and/or quality of input. Mayberry and Kluender (2017) should therefore reconsider their view that years of L2 use provides an adequate measure of input (see Flege, 2009) and the notion that an "end state" exists for L2 speech learning. Flege et al. (in preparation) measured VOT in English stops produced by 150 Italians at two times separated by 10.4 years. Despite a strong overall correlation, $r(148)=0.84$, 20 Italian participants increased VOT by an average 18 msec from T1 to T2 whereas 20 others decreased VOT by the same amount. The Italians who increased VOT reported using English more at T2 than T1 whereas those who decreased VOT reported using English less.

\section{References}

Flege, J., \& MacKay, I. (2004). Perceiving vowels in a second language. Studies in Second Language Acquisition, 26, $1-34$.

Flege, J., \& MacKay, I. (2011). What accounts for "age" effects on overall degree of foreign accent? In M. Wrembel et al. (eds.), Achievements and Perspectives in the Acquisition of Second Language Speech. New Sounds 2010, Vol. 2, pp. 65-82. Bern: Peter Lang.

Flege, J. (2007). Language contact in bilingualism: Phonetic system interactions. In J. Cole \& J. Hualde (eds.), Laboratory Phonology 9, pp. 353-380. Berlin: Mouton de Gruyter.

Flege, J. (2009). Give input a chance! In T. Piske \& M. YoungScholten (eds.), Input Matters in SLA, pp. 175-190. Bristol: Multilingual Matters.

Flege, J., Birdsong, D., Bialystok, E., Mack, M., Sung, H., \& Tsukada, K. (2006). Degree of foreign accent in English sentences spoken by Korean children and adults. Journal of Phonetics, 34, 153-175.

Flege, J., Frieda, E., \& Nozawa, T. (1997). Amount of nativelanguage (L1) use affects the pronunciation of an L2. Journal of Phonetics, 25, 169-186.

Flege, J., MacKay, I., \& Munro, M. (1995). Factors affecting degree of perceived foreign accent in a second language. Journal of the Acoustical Society of America, 97, 31253134.

Flege, J., Yeni-Komshian, G., \& Liu, S. (1999). Age constraints on second language learning. Journal of Memory and Language, 41, 78-104.

Johnson, J., \& Newport, E. (1989). Critical period effects in second language learning: The influence of maturational state on the acquisition of English as a second language. Cognitive Psychology, 21, 60-99.

Lenneberg, E. (1967). Biological foundations of language. New York: John Wiley and Sons.

Mayberry, R. I., \& Kluender, R. (2017). Rethinking the critical period for language: New insights into an old question from American Sign Language. Bilingualism: Language and Cognition, doi: 10.1017/S1366728917000724 